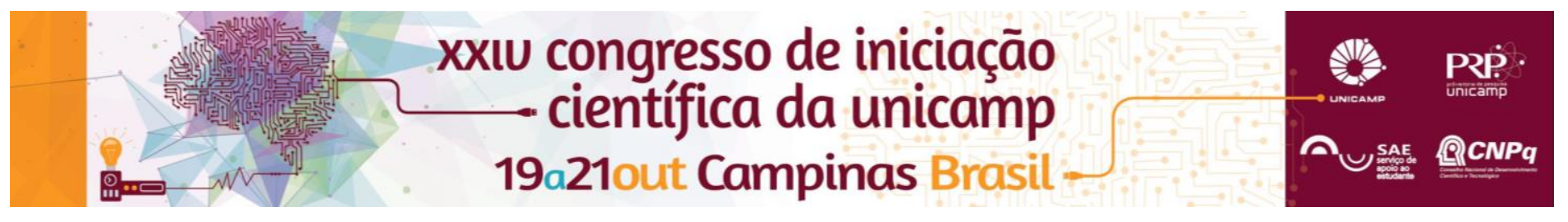

\title{
Biodiversidade dos Ophiuroidea da Ilha Trindade, Sudeste do Brasil
}

\author{
Helena Serrano*, Renata Alitto, Michela Borges
}

\section{Resumo}

Com o propósito de estudar a biodiversidade dos Ophiuroidea (Echinodermata) da llha Trindade, está sendo analisado o material procedente do Projeto Protrindade. Até o momento, foram analisados 694 espécimes de seis famílias. Os resultados obtidos com esse trabalho contribuirão de forma consistente para o conhecimento da biodiversidade dos Ophiuroidea na llha, gerando subsídios para futuras propostas de conservação e manejo.

\section{Palavras-chave: Projeto Protrindade, taxonomia, equinodermos.}

\section{Introdução}

Os Echinodermata caracterizam-se pelo esqueleto de carbonato de cálcio, sistema hidrovascular de canais celômicos, simetria radial secundária e tecido conectivo mutável'. Dentre estes, os Ophiuroidea são os mais representativos com 2136 espécies descritas, ocorrendo nos mais diferentes ambientes marinhos. Possuem uma estrutura corporal simples, com disco bem delimitado e braços geralmente longos e delgados ${ }^{2}$. É considerado um dos grupos mais bem-sucedidos do filo devido à sua mobilidade, diversidade de hábitos alimentares $e$ tamanho pequeno, o que lhes permite acessar diferentes habitats. Apesar de tamanha representatividade, são poucos os estudos com o grupo, especialmente em torno de ilhas oceânicas distantes da costa, como por exemplo, a llha Trindade, localizada no Sudeste do Brasil. Esta é uma ilha protegida pela marinha, totalmente voltada para pesquisa e conservação. Com o propósito de estudar a biodiversidade dos Ophiuroidea da Ilha Trindade, foi analisado o material procedente do Projeto Protrindade para avaliação da diversidade e densidade desses organismos.

\section{Resultados e Discussão}

Até o momento, analisamos 694 espécimes, distribuídos em seis famílias, oito gêneros e 13 espécies. Além destes, identificamos 10 morfotipos em nível de gênero: Amphioplus (cinco morfotipos), Ophiothrix (quatro) e Ophiocoma (um). Estes morfotipos são, provavelmente, novas ocorrências para o Brasil e, alguns, estão sendo analisados como possíveis espécies novas para a Ciência. A família com maior riqueza foi Amphiuridae com seis espécies, seguida de Ophiocomidae, cinco, Ophiotrichidae cinco, Ophiactidae três, Ophiodermatidae duas e Ophiolepididae com uma espécie. Com relação à abundância, Ophiocomidae foi a família mais representativa com $36 \%$ do total de espécimes analisados, seguida de Ophiotrichidae (27\%), Amphiuridae (23\%), Ophiactidae (13\%), Ophiodermatidae (1\%) e Ophiolepididae (0,28\%) (Fig. 1). Dentre as espécies mais abundantes, destacamos: Ophiocomella ophiactoides (Ophiocomidae, 214 indivíduos), Ophiothrix sp. 1 (Ophiotrichidae, 146), Amphipholis squamata (Amphiuridae) e Ophiactis savignyi (Ophiactidae, 88). Nossos resultados foram semelhantes aos encontrados no Arquipélago de Saint Peter e Saint $\mathrm{Paul}^{3}$, onde a O. ophiactoides e O. savignyi também foram abundantes, o que os autores relacionam com a capacidade de fissiparidae destas espécies, mecanismo pelo qual os indivíduos se reproduzem de forma assexuada (clonagem).

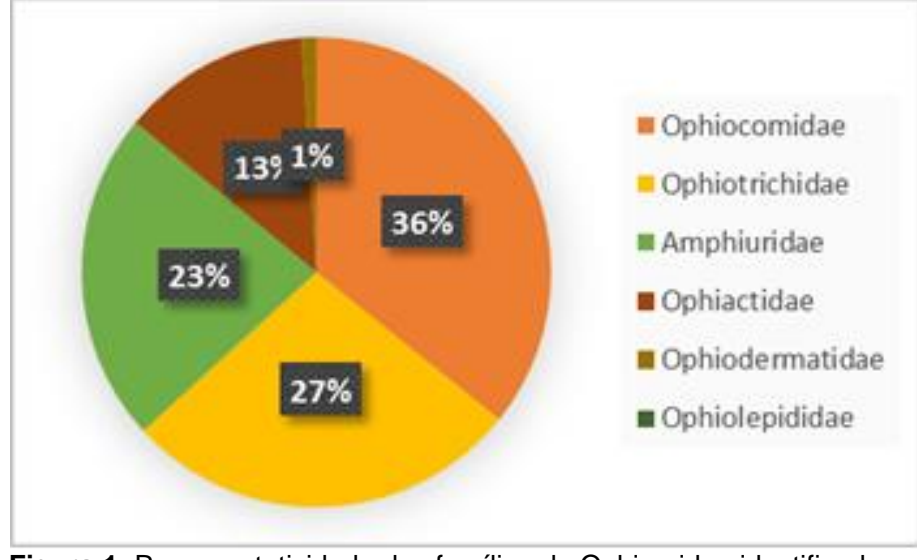

Figura 1. Representatividade das famílias de Ophiuroidea identificadas na llha Trindade.

\section{Conclusões}

A partir dos resultados até agora obtidos nas profundidades amostradas (cerca de $12 \mathrm{~m}$ ), observamos uma predominância das famílias Ophiocomidae, Ophiotrichidae e Amphiuridae, comuns em ambientes rasos também próximos ao continente. Tais resultados mostram que a fauna da llha é composta por espécies comuns à ecorregião Trindade e Martin Vaz. Esta ecorregião pertence à província Tropical do Atlântico Sudoeste, assim como o Arquipélago de Saint Peter e Saint Paul e todo o nordeste brasileiro. O trabalho encontra-se em andamento e mais amostras estão sendo examinadas. Espécimes ainda não identificados continuam sendo minuciosamente estudados.

\section{Agradecimentos}

Ao Projeto Protrindade por disponibilizar o material para o estudo.

\footnotetext{
${ }^{1}$ Hadel V.F., Monteiro A.M.G., Ditadi A.F., Tiago C.G. \& Tommasi L.R. 1999. Echinodermata. Em A.C. Migotto, \& C.G. Tiago, Biodiversidade do Estado de São Paulo, Brasil: síntese do conhecimento ao final do século XX São Paulo: FAPESP: 260-271.

2 Borges M., Yokoyama L.Q. \& Amaral A.C.Z. 2011. Ophiuroidea. Em: Biodiversidade e ecossistemas bentônicos marinhos do Litoral Norte de São Paulo. Campinas, SP: UNICAMP/IB: 280-288.

${ }^{3}$ Barboza C.A.M., Mattos G. \& Paiva, P.C. 2015. Brittle stars from the Saint Peter and Saint Paul Archipelago: morphological and molecular data, Marine Biodiversity Records 8: 1-9.
} 